\title{
Total Synthesis of Cochlearol B via a Catellani- and Visible Light-En- abled [2+2]-Cycloaddition Approach
}

\author{
Alistair D. Richardson, Trenton R. Vogel, Emily F. Traficante, Kason J. Glover, and Corinna S. Schindler*. \\ University of Michigan, Department of Chemistry, Willard Henry Dow Laboratory, 930 North University Ave., Ann Arbor, \\ MI 48109, US.
}

\section{Supporting Information Placeholder}

\begin{abstract}
A new, twelve-step approach towards the meroterpenoid cochlearol B is reported. This strategy takes advantage of a palladium-catalyzed Catellani reaction of a complex chromenyl triflate and a subsequent visible light-mediated [2+2]-cycloaddition to form the central bicyclo[3.2.0]heptane core of cochlearol B. Notably, careful selection and tuning of the photocycloaddition precursor proved crucial to differentiate between cyclopropanation reactions, [4+2] cycloadditions, and selective [2+2]-photocycloadditions.
\end{abstract}

In 2014, Cheng and co-workers reported the isolation of cochlearol A (1) together with cochlearol B (2) from the extracts of Ganoderma cochlear (Fig. 1A). ${ }^{1}$ Their studies were initially inspired by the known pharmacological effects of Ganoderma extracts, which are used in traditional Chinese medicine for the prevention and treatment of cancer, hypertension, chronic bronchitis, and asthma. ${ }^{2}$ In addition to cochlearol $\mathrm{A}$ and $\mathrm{B}$, a number of other structurally diverse meroterpenoids have been isolated from Ganoderma cochlear, including ganocin B (3, Fig. 1A) ${ }^{3}$ In comparison to cochlearol B (2), cochlearol A (1) is structurally less complex, incorporating a dioxaspiro[4.5]decane moiety. The structure of cochlearol B (2) was originally deduced based on NMR and HRMS analysis and shown to feature a 4/5/6/6/6-fused polycyclic ring system with a central hepta-substituted cyclobutane core, which includes three stereogenic centers and three quaternary carbon atoms. Both cochlearol B (2) and ganocin B (3) contain a common chromane core, however ganocin B possesses a structurally distinct spiro[4,5]decane ring. ${ }^{3}$ Notably, both cochlearol A (1) and cochlearol B (2) were isolated as racemates and were shown to exert renoprotective effects on renofibrosis by inhibiting upregulation of collagen I, fibronectin, and $\alpha$-SMA. ${ }^{1}$ Interestingly, only (-)cochlearol B (2) demonstrated potent antifibrotic efficacy while (+)-2 was found to be inactive. Furthermore, additional studies suggested that (-)-2 efficiently inhibits the phosphorylation of Smad2 and Smad 3 and consequently disrupts Smad 2 and Smad 3 activation whereas (+)-2 does not. While both cochlearol A (1) and cochlearoid B (3) have been the target of several established synthetic strategies4,5, only one racemic approach to cochlearol B (2) has been reported6 despite its unique architecture.

Our retrosynthetic analysis of cochlearol B (2) relied on an intramolecular aldol condensation to form the $\alpha, \beta$-unsaturated aldehyde moiety from cyclobutane 4 (Fig. 1B). We envisioned building both the 4- and 5-membered ring systems simultaneously in an intramolecular, visible light-mediated
Figure 1. A. Ganoderma meroterpenoids including cochlearol B (2). B. Retrosynthetic strategy towards cochlearol B (2) relying on Catellani and [2+2]-cycloaddition reactions.

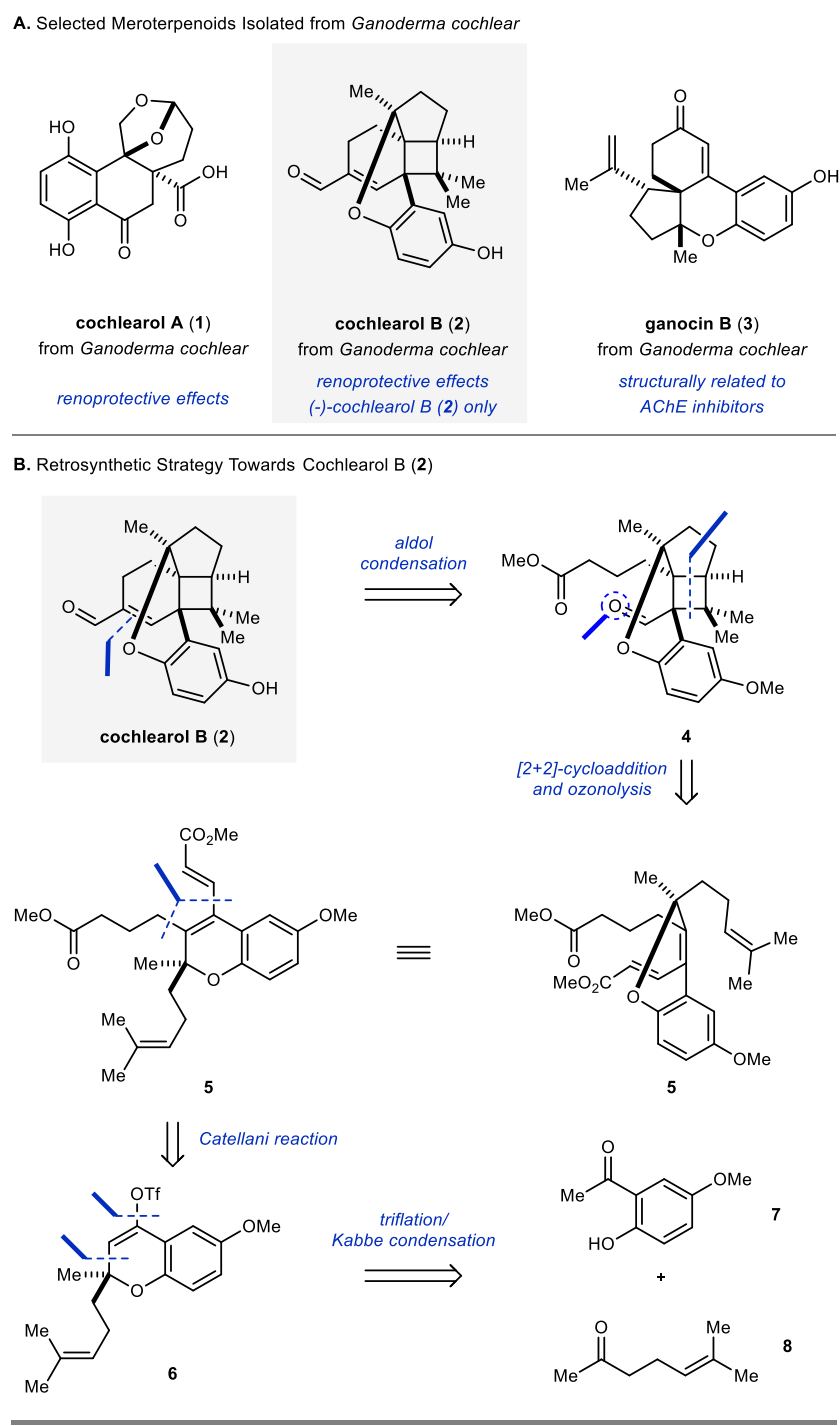

$[2+2]$-cycloaddition of chromene 5 . Introduction of the two methyl ester fragments in $\mathbf{5}$ could proceed concomitantly in a palladiumcatalyzed Catellani reaction ${ }^{7,8,9}$ of triflate $\mathbf{6}$. 
Figure 2. Triflation of chromanone 11 yields unexpected cyclopentylchormene $\mathbf{1 2}$ common to ganocins A-C (3).'

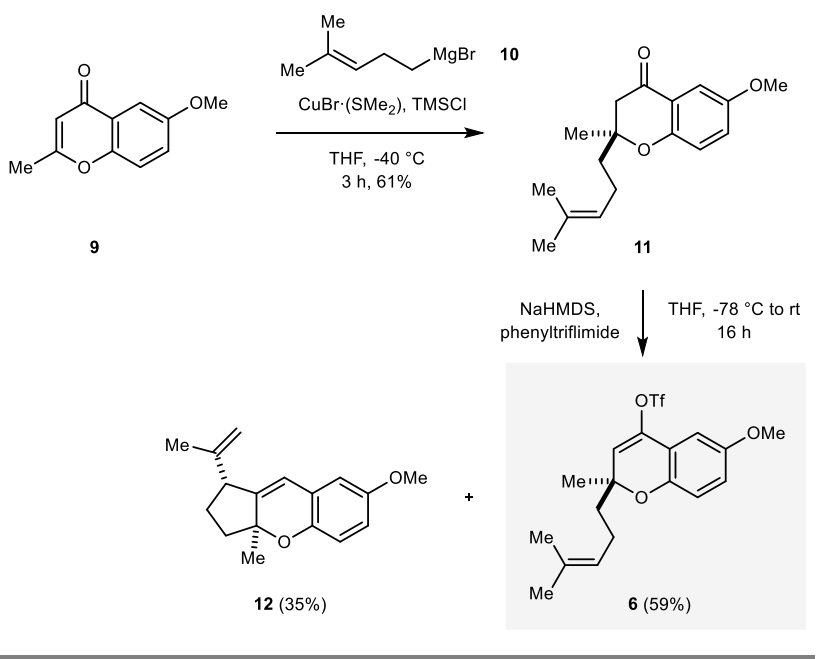

This represents one of the more complex precursors used in this class of transformations to date. ${ }^{10-23}$ Triflate 6 is accessible through a Kabbe condensation ${ }^{24}$ of commercially available precursors phenol 7 and 6-methylhept-5-en-2-one (8). ${ }^{25}$

In initial studies towards cochlearol B (2), we were able to access 6-methoxy-2-methyl-4H-chromen-4-one (9) via a one-pot acylation, Baker-Venkataraman rearrangement, ${ }^{26}$ and condensation of 7 using conditions developed by Brown and coworkers. ${ }^{27}$ A subsequent 1,4-conjugate addition ${ }^{28}$ of 9 with homoprenyl magnesium bromide (10) in the presence of catalytic amounts of $\mathrm{CuBr} \cdot\left(\mathrm{SMe}_{2}\right)$ initially gave rise to chromanone $\mathbf{1 1}$ in $34 \%$ yield. Forming the corresponding oxypyrilium ion of $\mathbf{9}$ upon addition of stoichiometric amounts of $\mathrm{TMSCl}^{29}$ proved beneficial and increased the yield of
11 to $61 \%$ (Fig. 2). The subsequent triflation of chromanone 11 proved more challenging than expected. In addition to isolating $59 \%$ of vinyl triflate $\mathbf{6}$, cylcopentylchromene $\mathbf{1 2}$ was isolated in $35 \%$ yield. This tricyclic structure is also featured in ganocins AC. To overcome this undesired reactivity, Comin's reagent ${ }^{30}$ was evaluated as an alternative to phenyltriflimide. This more reactive triflating agent enabled the reaction to proceed at cryogenic temperatures in shorter reaction times and eliminated the formation of 12 and improved the yield of 6 up to 86\% (Fig. 5).

Vinyl triflate 6 was subsequently subjected to Catellani conditions ${ }^{9}$ to enable concomitant ortho and ipso alkylation to provide tetrasubstituted alkene 5 in $30 \%$ yield (Fig. 3A). However, efforts to optimize this transformation could not overcome the formation of undesired byproduct 14, which forms in up to $11 \%$ yield likely in a thermal [4+2]-cycloaddition. Importantly, subsequent studies confirmed that alkene $\mathbf{1 4}$ forms exclusively upon heating of $\mathbf{1 5}$ to $100{ }^{\circ} \mathrm{C}$ in dioxane, which is consistent with the [4+2]-cycloaddition hypothesis. Compound $\mathbf{1 5}$ likely forms in situ via a direct Heck reaction $^{31}$ of vinyl triflate $\mathbf{6}$ and methyl acrylate that directly competes with the desired Catellani reaction. Subsequently, when tetrasubstituted alkene $\mathbf{5}$ was subjected visible light-mediated $[2+2]$-cycloaddition conditions, ${ }^{32,33}$ none of the desired cyclobutane 16 was formed. The only product isolated was identified as cyclopropane $\mathbf{1 7}$ in $85 \%$ yield (Fig. 3B). We hypothesize that this unexpected product arises upon initial photochemical excitation of the styrenyl olefin in $\mathbf{5}$ to its excited state 18. The resulting biradical subsequently reacts with the homoprenyl subunit to form the first five-membered ring (19). However, instead of forming the desired cyclobutane upon radical combination, a second addition to the electrophilic carbon of the methyl acrylate fragment occurs, resulting in the second five-membered ring (20) and ultimately cyclopropane 17 upon radical recombination (Fig. 3C). Notably, the evaluation of multiple photocatalysts exhibiting distinct triplet energies ${ }^{34}$ (e.g. $\left.\left[\mathrm{Ru}(\mathrm{byp})_{3}\right]\left(\mathrm{PF}_{6}\right)_{2},\left[\operatorname{Ir}\left(\mathrm{dF}\left(\mathrm{CF}_{3}\right) \text { ppy }\right)_{2}(\mathrm{dtbpy})\right]\left(\mathrm{PF}_{6}\right)\right)$, as well as direct excitation with UV light, did not result in the formation of

Figure 3. Challenges observed in developing a Catellani and subsequent [2+2]-cycloaddition approach towards cochlearol B (2).

A. First Generation Catellani Approach: Challenges due to Competing [4+2] Cycloaddition
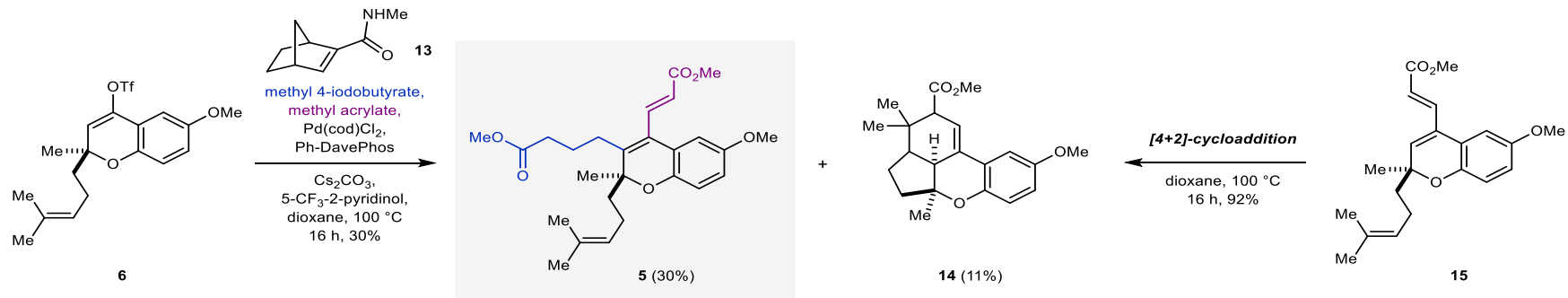

B. [2+2]-Cycloaddition: Challenges due to Competing Cyclopropanation
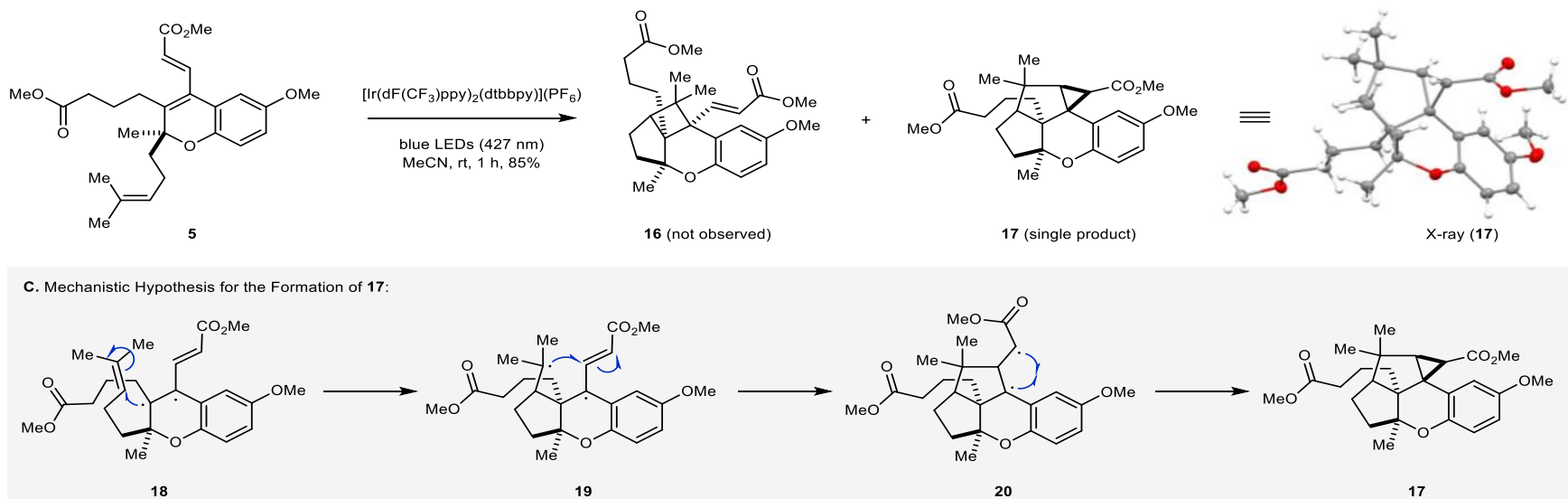

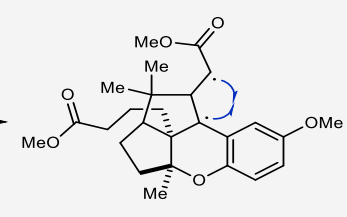

20
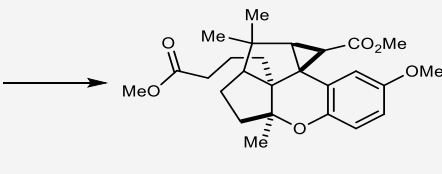
Figure 4. Proof-of-principle for a visible light-enabled [2+2]-cycloaddition strategy towards cochlearol B (2).
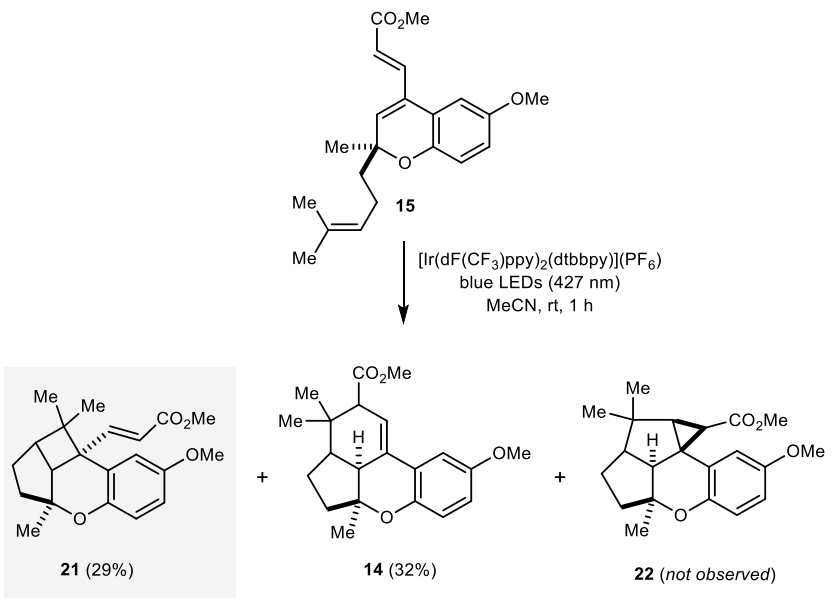

cyclobutane 16 and cyclopropane 17 remained the exclusive product formed.

To gain support for this mechanistic hypothesis, as well as investigate how to overcome this reactivity, we next evaluated the role of steric and electronic effects of the substituents by subjecting 15 to the conditions for $[2+2]$-cycloadditions (Fig. 4). Although 15 is electronically comparable to 5 , no formation of cyclopropane 22 was observed. Instead, a mixture of the [2+2]- and [4+2]- cycloadducts 21 and 14 were isolated in $29 \%$ and $32 \%$ yield, respectively. These results suggest that steric constraints of the methyl acrylate and methyl butyrate chains favor the formation of cyclopropane $\mathbf{1 7}$ over cyclobutane 16. This is consistent with $\mathbf{1 7}$ being isolated as a single diastereomer incorporating the cyclopropane and methyl butyrate chains on opposite faces. Furthermore, in addition to the steric constraints, we hypothesized that the electrophilic nature of the acrylate moiety in $\mathbf{1 9}$ together with the high stability of the resulting biradical in $\mathbf{2 0}$ favors the formation of cyclopropane 17. As a result of these insights, we revised our synthetic strategy towards cochlearol B (2). Specifically, we postulated that a less reactive alkene could mitigate the competing Heck reaction in the Catellani step, while a conformationally restricted diene was expected to prevent undesired [4+2]-cycloadditions. Our final synthetic approach towards cochlearol B (2) takes advantage of these insights and combines a Kabbe condensation ${ }^{24}$ to access chromanone $\mathbf{1 1}$ with a revised design for the Catellani reaction to ultimately enable a productive [2+2]-cycloaddition by foregoing competing Heck, [4+2]cycloaddition, and cyclopropanations (Fig. 5). Specifically, a pyrrolidine-catalyzed condensation between $\mathbf{7}$ and $\mathbf{8}$ forms chromanone $\mathbf{1 1}$ directly in a $76 \%$ yield while subsequent treatment with Comin's reagent resulted in triflate 6 in $86 \%$ yield. Subjecting 6 to Catellani conditions with commercially available 5-iodo-1-pentene ${ }^{9}$, which functions as both the nucleophilic and electrophilic coupling partner, gives rise to chromene $\mathbf{2 3}$ incorporating an $s$-trans diene that establishes the third 6-membered ring common to cochlearol B (2). This intermediate was expected to exhibit distinct advantages compared to chromene $\mathbf{5}$. In particular; 1) the locked $s$ trans conformation of the diene in $\mathbf{2 3}$ prevents the formation of a competing thermal $[4+2]$-cycloadduct under Catellani reaction conditions, while 2) the absence of a methyl acrylate moiety disfavors cyclopropanation as the alkene is now less electrophilic and the resulting radical is no longer stabilized by an adjacent carbonyl; 3 ) forming the third six membered ring prior to the [2+2]-cycloaddition eliminates the steric constraints that previously precluded the formation of cyclobutane 16. Importantly, these suppositions were reinforced with the isolation of chromene $\mathbf{2 3}$ as the exclusive product. Remarkably, this reaction was amenable to gram scale resulting in the formation of the desired product in up to $81 \%$ yield. With a viable route to the photocycloaddition precursor established, diene 23 was subjected to visible light-enabled [2+2]-cycloaddition conditions giving rise to the pentacyclic cyclobutane $\mathbf{2 4}$, as the sole product in $94 \%$ yield. Notably, irradiation of chromene 23 with UV-light in the absence of a photocatalyst failed to provide the desired product $\mathbf{2 4}$. The terminal alkene in $\mathbf{2 4}$ was subsequently converted in a two-step dihydroxylation ${ }^{35}$ and oxidative cleavage ${ }^{36}$ sequence to obtain ketone $\mathbf{2 5}$ in $40 \%$ overall yield. In order to incorporate the desired $\alpha, \beta$-unsaturated aldehyde characteristic for chochlearol B (2), ketone 25 was first subjected to a condensation reaction with DMF-DMA ${ }^{37}$ yielding enaminone 26 in $86 \%$ yield. Upon subsequent triflation ${ }^{38}$, the resulting vinyl triflate was subjected to palladium catalyzed reduction conditions ${ }^{39}$ providing 27 in $76 \%$ yield over two steps. Completion of the synthesis of cochlearol B (2) required final deprotection of the phenol in 27 , which proved challenging due to the stability of $\mathbf{2 7}$ under Lewis acidic

Figure 5. Development of an efficient strategy towards cochlearol B (2) relying on a Catellani reaction and visible light-mediated [2+2]cycloaddition.

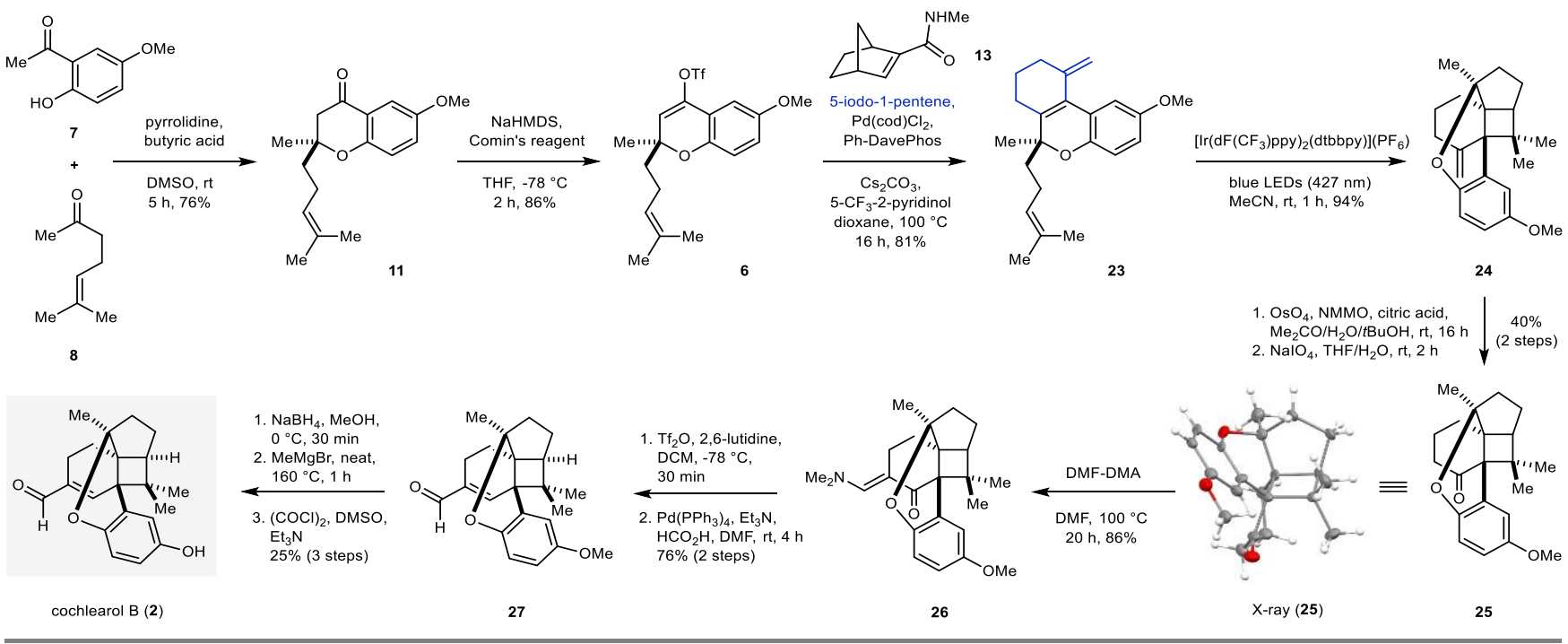


and nucleophilic demethylation conditions. However, following a reduction of the aldehyde with $\mathrm{NaBH}_{4}$, demethylation of the phenol was successfully achieved upon treatment with neat $\mathrm{MeMgI}^{40}$ at elevated temperatures to complete the synthesis of cochlearol B (2) after final Swern oxidation in $25 \%$ yield over the final 3 steps and in 12 overall steps from commercially available materials.

\section{ASSOCIATED CONTENT}

\section{Supporting Information}

The Supporting Information is available free of charge on the ACS Publications website and includes experimental procedures, characterization $\left({ }^{1} \mathrm{H}-\mathrm{NMR},{ }^{13} \mathrm{C}-\mathrm{NMR}\right.$, IR, and MS data), additional optimization and control experiments (pdf format). $-\mathrm{dfj}$

\section{AUTHOR INFORMATION}

\section{Corresponding Author}

*Email: corinnas@umich.edu.

\section{Notes}

The authors declare no competing financial interests.

\section{ACKNOWLEDGMENT}

We thank the National Science Foundation (NSF CHE-1654223), the Alfred P. Sloan Foundation (CSS), the David and Lucile Packard Foundation (CSS) the Camille and Henry Dreyfus Foundation (CSS) for financial support. ADR thanks BMS for a predoctoral fellowship and the Rackham Graduate School of the University of Michigan for a dissertation fellowship.

\section{REFERENCES}

(1) Dou, M.; Di, L.; Zhou, L.-L.; Yan, Y.-M.; Wang, X.-L.; Zhou, F.-J.; Yang, Z.-L.; Li, R.-T.; Hou, F.-F.; Cheng, Y.X. Cochlearols A and B, Polycyclic Meroterpenoids from the Fungus Ganoderma cochlear That Have Renoprotective Activities. Org. Lett. 2014, 16, 6064-6067. https://doi.org/10.1021/ol502806j.

(2) Russell, R.; Paterson, M. Ganoderma - A therapeutic fungal biofactory. Phytochemistry 2006, 67, 1985-2001. https://doi.org/10.1016/j.phytochem.2006.07.004.

(3) Peng, X.-R.; Liu, J.-Q.; Wan, L.-S.; Li, X.-N.; Yan, Y.-X.; Qiu, M.-H. Four New Polycyclic Meroterpenoids from Ganoderma cochlear. Org. Lett., 2014, 16, 5262-5265. https://doi.org/10.1039/C6OB02049F.

(4) For approaches towards cochlearol A a), see: a) Zhang, D.-W.; Xu, W.-D.; Fan, H.-L.; Liu, H.-M.; Chen, D.; Liu, D.-D.; Qin, H.-B. Total Synthesis of ( \pm )-Cochlearol A. Org. Lett. 2019, 21, 6761-6764. https://doi.org/10.1021/acs.orglett.9b02391; b) Naruse, K.; Katsuta, R.; Yajima, A.; Nukada, T.; Watanabe, H.; Ishigami, K. Formal Synthesis of cochlearol A, a meroterpenoid with renoprotective activity. Tetrahedron Lett. 2020, 61, 151845; c) Venkatesh, T.; Mainkar, P.S.; Chandrasekhar, S. Diastereoselective Formal Synthesis of Polycyclic Meroterpenoid ( \pm )-Cochlearol A. J. Org. Chem. 2021, 86, 5412-5416.

(5) Liu, Y.; Zhou, C.-J.; Li, Q.; Wang, H. Total synthesis of ( \pm ganocins B and C. Org. Biomol. Chem., 2016, 14, 1036210365. https://doi.org/10.1039/C6OB02049F.

(6) Mashiko, T.; Shingai, Y.; Sakai, J.; Kamo, S.; Adachi, S.; Matsuzawa, A.; Sugita, K. Total Synthesis of Cochlearol B via Intramolecular [2+2]-Photocycloaddition. Angew. Chem. Int. Ed. 2021, 60, 24484-24487. https://doi.org/10.1002/anie.202110556.

(7) Catellani, M.; Frignani, F.; Rangoni, A. A complex catalytic cycle leading to a regioselective synthesis of o,o'-disubstituted vinylarenes. Angew. Chem. Int. Ed. 1997, 36, 119-122. https://doi.org/10.1002/anie.199701191.
(8) a) Catellani, M.; Motti, E.; Della, Ca', N. Catalytic sequential reactions involving palladacycle-directed aryl coupling steps. Acc. Chem. Res. 2008, 41, 1512-1522; https://doi.org/10.1021/ar800040u; b) Della, Ca',N.; Fontana, M.; Motti, E.; Catellani, M. Pd/Norbornene: a winning combination for selective aromatic functionalization via $\mathrm{C}-\mathrm{H}$ bond activation. Acc. Chem. Res. 2016, 49, 1389-1400. https://doi.org/10.1021/acs.accounts.6b00165.

(9) Wang, J.; Dong, Z.; Yang, C.; Dong, G. Modular and regioselective synthesis of all-carbon tetrasubstituted olefins enabled by an alkenyl Catellani reaction. Nat. Chem. 2019, 11, 11061112. https://doi.org/10.1038/s41557-019-0358-y.

(10) Lautens, M.; Piguel, S. A new route to fused aromatic compounds by using a palladium-catalyzed alkylation-alkenylation sequence. Angew. Chem. Int. Ed. 2000, 39, 1045-1046.

(11) Catellani, M.; Motti, E.; Baratta, S. A novel palladium-catalyzed synthesis of phenanthrenes from ortho-substituted aryl iodides and diphenyl- or alkylphenylacetylenes. Org. Lett. 2001, 3, 3611-3614. https://doi.org/10.1021/o1016360o.

(12) Faccini, F.; Motti, E.; Catellani, M.; A new reaction sequence involving palladium-catalyzed unsymmetrical aryl coupling. $J$. Am. Chem. Soc. 2004, 126, 78-79. https://doi.org/10.1021/ja039043g.

(13) Blaszykowski, C.; Aktoudianakis, E.; Bressy, C.; Alberico, D.; Lautens, M. Preparation of annulated nitrogen-containing heterocycles via a one-pot palladium-catalyzed alkylation/direct arylation sequence. Org. Lett. 2006, 8, 2043-2045. https://doi.org/10.1021/ol060447y.

(14) Gericke, K.M.; Chai, D.I.; Bieler, N.; Lautens, M. The norbornene shuttle: multicomponent domino synthesis of tetrasubstituted helical alkenes through multiple $\mathrm{C}-\mathrm{H}$ functionalizations. Angew. Chem. Int. Ed. 2009, 48, 1447-1451. https://doi.org/10.1002/anie.200805512.

(15) Martins, A.; Mariampillai, B.; Lautens, M. Synthesis in the key of Catellani: norbornene-mediated ortho $\mathrm{C}-\mathrm{H}$ functionalization. Top. Curr. Chem. 2010, 292, 1-33.

(16) Khanna, A.; Premachandra, I.D.U.A.; Sung, P.D.; Van Vranken, D.L. Palladium-catalyzed Catellani aminocyclopropanation reactions with vinyl halides. Org. Lett. 2013, 15, 3158-3161. https://doi.org/10.1021/ol401383m.

(17) Zhang, H.; Chen, P.; Liu, G. Palladium-catalyzed cascade C-H trifluoroethylation of aryl iodides and heck reaction: efficient synthesis of ortho-trifluoroethylstryenes. Angew. Chem. Int. Ed. 2014, 53, 10174-10178. https://doi.org/10.1002/anie.201403793.

(18) Ye, J.; Lautens, M. Palladium-catalysed norbornene-mediated C-H functionalization of arenes. Nat. Chem. 2015, 7, 863-870. https://doi.org/10.1038/nchem.2372.

(19) Qureshi, Z.; Schlundt, W.; Lautens, M. Introduction of hindered electrophiles via $\mathrm{C}-\mathrm{H}$ functionalization in a palladiumcatalyzed multicomponent domino reaction. Synthesis $\mathbf{2 0 1 5}$, 47, 2446-2456. https://doi.org/10.1055/s-0034-1380198.

(20) Dong, Z.; Wang, J.; Ren, Z. Dong, G. Ortho C-H acylation of aryl iodides by palladium/norbornene catalysis. Angew. Chem. Int. $\quad E d$. 2015, $\quad 54, \quad$ 12664-12668. https://doi.org/10.1002/anie.201506397.

(21) Liu, Z.-S.; Gao, Q.; Cheng, H.-G.; Zhou, Q. The alkylating reagents employed in catellani-type reactions. Chem. Eur. J. 2018, 24, 15461-15476. https://doi.org/10.1002/chem.201802818.

(22) Yamamoto, Y.; Murayama, T.; Jiang, J.; Yasui, T.; Shibuya, M. The vinylogous Catellani reaction: a combined computational and experimental study. Chem. Sci. 2018, 9, 1191-1199. https://doi.org/10.1039/C7SC04265E.

(23) Wang, J.; Dong, G. Palladium/Norbornene cooperative catalysis. Chem. Rev. 2019, 119, 7478-7528. https://doi.org/10.1021/acs.chemrev.9b00079.

(24) Kapuriya, N.P.; Bhalodia, J.J.; Ambasana, M.A.; Patel, R.B.; Bapodra, A.H. Organocatalyzed Kabbe condensation reaction for mild and expeditious synthesis of 2,2-dialkyl and 2-spiro- 
4-chromanones. J. Heterocycl. Chem. 2020, 57, 3369-3374. https://doi.org/10.1002/jhet.4054

(25) 2'-hydroxy-5'-methoxyacetophenone and 6-methylhept-5-en2-one were commercially obtained from Sigma Aldrich.

(26) (a) Baker, W. Molecular Rearrangement of Some O-Acyloxyacetophenones and the mechanism of the production of 3Acylchromones. J. Chem. Soc. 1933, 1381-1389; (b) Mahal, H.S.; Venkataraman, K. Synthetic Experiments in the Chromone Group. Part XIV. The Action of Sodamide on 1Acyloxy-2-acetonaphthones. J. Chem. Soc. 1934, 1767-1769; (c) Ameen, D.; Snape, T.J. Mechanism and Application of Baker-Venkataraman O-C Acyl Migration Reactions. Synthesis. 2015, 47, 141-158.

(27) Ghani, S. B. A.; Mugisha, P.J.; Wilcox, J. C.; Gado, E.A.M.; Medu, E. O.; Lamb, A. J.; Brown, R. C. D. Convenient OnePot Synthesis of Chromone Derivatives and Their Antifungal and Antibacterial Evaluation. Synth. Commun. 2013, 43, 15491556. https://doi.org/10.1080/00397911.2011.647222

(28) Gallen, M.J.; Williams, C.M. Total synthesis of ( \pm )-5,14-bisepi-Spirovibsanin A. Org. Lett. 2008, 10, 713-715. https://doi.org/10.1021/o1702827x.

(29) Jeong, Y.; Moon, Y.; Hong, S. Tandem Dehydrogenation/Oxidaiton/Oxidative Cyclization Apporach to Wrightiadione and Its Derivatives. Org. Lett. 2015, 17, 3252-3255. https://doi.org/10.1021/acs.orglett.5b01618.

(30) Comins, D.L.; Dehghani, A. Pyridine-Derived Triflating Reagents: An Improved Preparation of Vinyl Trifaltes from Metallo Enolates. Tetrahedron Lett. 1992, 33, 6299-6302. https://doi.org/10.1016/S0040-4039(00)60957-7.

(31) Scott, W.J.; Peña, M.R.; Swärd, K.; Stoessel, S.J.; Stille, J.K. Palladium-Catalyzed Olefination of Vinyl Triflates. J. Org. Chem. 1985, 50, 2302-2308. https://doi.org/10.1021/jo00213a021; b) Reddy, C.R.; Srikanth, B.; Rao, N.N.; Shing. D.-S. Solid-supported acid-catalyzed C3-alkylation of 4-hydroxycoumarins with secondary benzyl alcohols: access to 3,4-disubstituted coumarins via Pdcoupling. Tetrahedron, 2008, 64, 11666-11672. https://doi.org/10.1016/j.tet.2008.10.017.

(32) a) Lu, Z.; Yoon, T.P. Visible light Photocatalysis of [2+2] Styrene Cycloadditions by Energy Transfer. Angew. Chem. Int. Ed. 2012, 51, 10329-10332. https://doi.org/10.1002/anie.201204835. b) Hurtley, A.E.; Lu, Z.; Yoon, T.P. [2+2] Cycloaddition of 1,3-Dienes by Visible Light Photocatalysis. Angew. Chem. Int. Ed. 2014, 53, 89918994. https://doi.org/10.1002/anie.201405359.

(33) a) Poplata, S.; Tröster, A.; Zou, Y.Q.; Bach,T. Recent Advances in the Synthesis of Cyclobutanes by Olefin [2+2] Photocycloaddition Reactions. Chem. Rev. 2016, 116, 9748-9815. https://doi.org/10.1021/acs.chemrev.5b00723; b) Skubi, K.L. ; Blum, T.R. ; Yoon, T.P. Dual Catalysis Strategies in Photochemical Synthesis. Chem. Rev. 2016, 116, 10035-10074. https://doi.org/10.1021/acs.chemrev.6b00018.

(34) Teegardin, K.; Day, J.I.; Chan, J.; Weaver, J. Advances in Photocatalysis: A Microreview of Visible Light Mediated Ruthenium and Iridium Catalyzed Organic Transformations. Org. Process. Res. Dev. 2016, 20, 1156-1163. https://doi.org/10.1021/acs.oprd.6b00101.

(35) a) Dupau, P.; Epple, R.; Thomas, A.A.; Fokin, V.V.; Sharpless, K.B. Osmium-Catalyzed Dihydroxylation of Olefins in Acidic Media: Old Process, New Tricks. Adv. Synth. Catal 2002, 344 , 421-433; b) Chu, H.; Smith, J.M.; Felding, J.; Baran, P.S. Scalable Synthesis of (-)-Thapsigargin. ACS, Cent. Sci. 2017, 3, 47-51. https://doi.org/10.1021/acscentsci.6b00313.

(36) Sudalai, A.; Khenkin, A.; Neumann, R. Sodium periodate mediated oxidative transformations in organic synthesis. Org. Biomol. Chem. 2015, 13, 4374-4394. https://doi.org/10.1039/C5OB00238A.

(37) Frolov, A.I.; Ostapchuk, E.N.; Pashenko, A.E.; Chuchvera, Y. O.; Rusanov, E.B.; Volochnyuk, D. M.; Ryabukhin, S.V. Selective $\alpha$-Methylation of Ketones. J. Org. Chem. 2021, 86, 7333-7346. https://doi.org/10.1021/acs.joc.1c00148.

(38) a) Shiina, Y.; Tomata, Y.; Miyashita, M.; Tanino, K. Asymmetric Total Synthesis of Glycinoeclepin A: Generation of a Novel Bridgehead Anion Species. Chem. Lett. 2010, 39, 835-837. https://doi.org/10.1246/cl.2010.835; b) Kotoku, N.; Mizushima, K.; Tamura, S.; Kobayahsi, M. Synthetic Studies of Cortistatin A Analogue from the CD-Ring Fragment of Vitamin D2. Chem. Pharm. Bull. 2013, 61, 1024-1029. https://doi.org/10.1248/cpb.c13-00375.

(39) Winkler, J.D.; Londregan, A.T.; Hamann, M.T. Antimalarial Activity of a New Family of Analogues of Manzamine A. Org. Lett. 2006, 8, 2591-2594. https://doi.org/10.1021/ol060848d; b) Hu, Y.; Bai, M.; Yang, Y.; Tian, J.; Zhou, Q. Rapid Access to Tetracyclic Core of Wortmannin via an Intramolecular Reductive Olefin Coupling Strategy. Org Lett. 2020, 22, 63086312. https://doi.org/10.1021/acs.orglett.0c02135.

(40) Hoye, T.R.; Humpal, P.E.; Moon, B. Total Synthesis of (-)-Cylindrocyclophane A via a Double Horner-Emmons Macrocyclic Dimerization Event. J. Am. Chem. Soc. 2000, 122, 4982-4983. https://doi.org/10.1021/ja000429q. 